\title{
Characterization of Silica Gels by 29Si MAS NMR and IR Spectroscopic Measurements
}

\begin{tabular}{|r|l|}
\hline Journal: & Zeitschrift für Anorganische und Allgemeine Chemie \\
\hline Manuscript ID: & zaac. 200900237.R1 \\
\hline Wiley - Manuscript type: & Article \\
\hline Date Submitted by the \\
Author: & 08-Jun-2009 \\
\hline Complete List of Authors: & $\begin{array}{l}\text { Lutz, Wolfgang; Süd-Chemie Zeolites GmbH } \\
\text { Täschner, Dirk; Süd-Chemie Zeolites GmbH } \\
\text { Kurzhals, Rolf; Süd-chemie Zeolites GmbH } \\
\text { Heidemann, Detlef; Humboldt-Universität } \\
\text { Hübert, Cornelia; Brandenburgisch Technische Universität }\end{array}$ \\
\hline Keywords: & $\begin{array}{l}\text { silicates, solid state structure, solvent effects, NMR spectroscopy, } \\
\text { IR spectroscopy }\end{array}$ \\
\hline \multicolumn{2}{|c}{} \\
\hline
\end{tabular}

\section{S ScholarONE" \\ Manuscript Central}


Characterization of silica gels by ${ }^{29} \mathrm{Si}$ MAS NMR and IR spectroscopic measurements

W. Lutz ${ }^{*}$, D. Täschner, R. Kurzhals, ${ }^{1}$ D. Heidemann, ${ }^{2}$ C. Hübert, Berlin and Bitterfeld, Süd-Chemie Zeolites GmbH, ${ }^{1}$ Berlin, Humboldt-Universität zu Berlin

${ }^{2}$ Cottbus, Brandenburgische Technische Universität

Received ........

\begin{abstract}
The solubility of commercial and synthesized silica gels in a solution of Tetra-EthylAmmonium-Hydroxide (TEAOH) was investigated at room temperature. The state of parent silica frameworks was characterized by BET and SEM. The structural defects were identified both by the $\mathrm{Q}^{\mathrm{n}}$ group analysis in ${ }^{29} \mathrm{Si}$ MAS NMR and IR spectroscopic investigation. It was found that the dissolution rate of the samples shows a tendency for growing up with an increasing BET surface. The increase of the internal surface was accompanied by formation of $\mathrm{Si}(\mathrm{OSi})_{3}(\mathrm{OH})\left(\mathrm{Q}^{3}\right)$ and $\mathrm{Si}(\mathrm{OSi})_{2}(\mathrm{OH})_{2}\left(\mathrm{Q}^{2}\right)$ structural units. The higher the number of $\mathrm{Q}^{3}$ and $\mathrm{Q}^{2}$ groups observed, the faster the samples were dissolved in TEAOH solution due to the attack of the hydroxide ions on the terminal $\mathrm{OH}$ groups of the framework. The asymmetrical TOT valence vibration of the IR spectra was systematically shifted to lower values with increase in the number of $\mathrm{Q}^{3}$ and $\mathrm{Q}^{2}$ structure groups.
\end{abstract}

Keywords: silica gel, preparation, solubility, ${ }^{29}$ Si MAS NMR and IR spectroscopy

\footnotetext{
* Wolfgang Lutz Süd-Chemie Zeolites GmbH, Labor Berlin, Volmerstr. 13, 12489 Berlin Tel.: 00493063924425

e-mail: wolfgang.lutz@sud-chemie.com
} 
Charakterisierung von Silicagelen mit Hilfe der IR- and ${ }^{29}$ Si MAS NMR-

Spektroskopie

\section{Inhaltsübersicht.}

Die Löslichkeit kommerzieller Silicagele und Gele eigener Herstellung in TEAOH-Lösung wurde bei Raumtemperatur untersucht. Die Löslichkeit stieg mit zunehmender Zahl von Strukturdefekten in der $\mathrm{SiO}_{2}$-Matrix, die mit Hilfe der $\mathrm{Q}^{\mathrm{n}}$-Gruppen-Analyse aus ${ }^{29} \mathrm{Si}$ MAS NMR-Spektren charakterisiert wurden. Die Wellenzahl der asymmetrische TOT $(\mathrm{T}=\mathrm{Si})$ Valenzschwingung in IR-Spektren verschob sich mit Zunahme der Strukturdefekte systematisch zu niedrigeren Werten. 


\section{Introduction}

Silica gels have been used in the chemical industry and laboratory technique as drying agents [1], feed stock of zeolite synthesis [2], and separation medium in chromatography [3] for a long period. More recently, they were applied also as wafer of optical sensors [4] and for heat storage by water sorption [5]. Pioneers reporting the physical and chemical properties of silica gels are Hauser [6], Sosman [7], or Hinz [8]. A general view about "The chemistry of silica" was published in 1979 by Iler [9].

Engelhardt and Michel [10] characterized the framework of silica gels by the $\mathrm{Q}^{\mathrm{n}}$ group analysis $\left(\mathrm{n}=\right.$ number of bridging oxygen atoms in the $\mathrm{SiO}_{4}$-tetrahedron under study) and Cannes [11] reported on the surface properties by the characterization of silanol groups by means of ${ }^{29}$ Si MAS NMR and CP MAS NMR experiments. IR spectroscopic measurements gave information about surface $\mathrm{OH}$-groups $[11,12]$ and the $\mathrm{SiO}_{2}$ framework [13].

The application of silica gels for the synthesis of zeolites was described in detail by Breck [1], Barrer [2], and Zhdanov [14]. The synthesis process of these aluminosilicates follows quite different recipes. The particle size, size distribution, and shape of the crystals obtained are decisively determined by the crystallization kinetics. All parameters depend on the temperature, alkalinity and composition of the synthesis batch, and, finally, the type of silica source. While in the classical synthesis of 4A (LTA) and X (FAU) zeolites water glass solution is used as silicate component, the synthesis of zeolites beta (BEA), mordenite (MOR), or ZSM-5 (MFI) involves the silica gels.

The reactivity of silica gels depends on their solubility in the alkaline mother liquors of the synthesis batches. Mechanism, kinetics and, consequently, the quality of the final products are thereby influenced by the size of $\mathrm{SiO}_{2}$ particles as well as by the condensation state of the $\mathrm{SiO}_{2}$ network. The crystal shape can be characterized by the scanning electron microscopic 
investigation (SEM) and the solubility by chemical analysis of the liquid phase. ${ }^{29} \mathrm{Si}$ MAS NMR and IR measurements can give direct hints to the state of the $\mathrm{SiO}_{2}$ framework.

This paper is aimed to demonstrate the applicability of the ${ }^{29} \mathrm{Si}$ MAS NMR as well as the IR spectroscopy as suitable methods for the efficient characterization of the framework state of silica gels, using two differently prepared sample series. 


\section{$2 \quad$ Experimental}

\section{Materials}

Commercial silica gels used for different zeolite synthesis processes and shown in Tab. 1 as well as synthesized silica gels were investigated. The latter were prepared according to the following route. The aqueous solution of sodium silicate was transformed into acid silica sol using "Wofatit KPS 200" as ion exchanger resin. $220 \mathrm{ml}$ silicate solution (1.8 $\mathrm{M}$ in $\left.\mathrm{SiO}_{2}\right)$ was dropped into a stirred batch of $1000 \mathrm{ml}$ resin and $200 \mathrm{ml}$ water at $278 \mathrm{~K}$ within 10 minutes. The acidity of the as-synthesized silica sol with $\mathrm{pH}$ of 2 was adjusted to $\mathrm{pH}$ values between 3 and 8 by immediate adding of sodium hydroxide solution. $\mathrm{SiO}_{2}$ xerogels were obtained by drying of the washed hydrogels at $383 \mathrm{~K}$ for 24 hours and subsequent crushing.

\section{Solubility experiments}

$1 \mathrm{~g}$ silica gel was stirred at ambient temperature in $40 \mathrm{ml}$ of a $15 \%$ aqueous solution of TEAOH for 15 - 60 minutes. Before ICP OES element analysis, the solution was separated from the solid by filtration over glass micro filters MF 100 (Fisherbrand) in a first step followed by the filtration using PTFE miro-membrans $(0.2 \mu \mathrm{m})$ under pressure within 5 minutes. The separation period was part of the total treatment time. The solubility of the glass filter material does not exceed $3 \mathrm{mg} / \mathrm{l}$ and can be, therefore, neglected. Cellulose membranes were non-suitable for the separation procedure because the material dissolves itself under these conditions.

The filtrates were analyzed by use of a IRIS Intrepid High Resolution spectrometer (Thermo Elemental, USA). The ICP OES was calibrated within reference to synthesized solution standards. The accuracy of the measurements lies around 1-3\% within relative standard deviation (RSD) for values above background equivalent concentration (BEC). 


\section{Characterization of xerogels}

The ${ }^{29} \mathrm{Si}$ MAS NMR spectra were recorded at room temperature on a Bruker Avance 400 spectrometer, operating at frequencies of $79.5 \mathrm{MHz}$. A $4 \mathrm{~mm}$ double tuned $\left({ }^{1} \mathrm{H}-\mathrm{X}\right) \mathrm{MAS}$ probe (Bruker Biospin) was used to perform MAS NMR measurements at spinning rates of $12 \mathrm{kHz}$. The spectra were obtained with a single pulse excitation consisting of $4 \mu$ s pulses $(\pi / 2$ pulses) and recycle delays of 120 seconds to exclude saturation effects. Up to 700 FIDs were accumulated to obtain reliable signal-to-noise ratio. The spectra were externally referenced to liquid $\mathrm{Me}_{4} \mathrm{Si}$ at $0 \mathrm{ppm}$. A detailed $\mathrm{Q}^{\mathrm{n}}$-group characterization includes the line shape analysis of the NMR spectra by use of an iterative deconvolution procedure with the help of dmfit software package [15].

IR absorption spectra were taken on a Shimadzu FTIR 8400 S spectrometer with a resolution of $\pm 1 \mathrm{~cm}^{-1}$ by use of 30 scans. For analysis, $0.5 \mathrm{mg}$ of the sample was pressed with $400 \mathrm{mg}$ $\mathrm{KBr}$ into a pellet and measured in the IR range of $400 \mathrm{~cm}^{-1}$ to $4000 \mathrm{~cm}^{-1}$.

Scanning electron microscopy (SEM) was performed on a Hitachi S2400 with W cathode at the accelerating potential of $15-20 \mathrm{kV}$. To produce the conductive layer, the particles were sputtered by a thin gold coating.

Chemical element analysis was measured by using XRF spectrometer PW2404 from Panalytical. 0,5 $\mathrm{g}$ of the sample were fused with $3 \mathrm{~g}$ lithium borate (Li4B6O11, Spectromelt A12 from Merck $\mathrm{GmbH}$ ) in a platinum crucible to cast a $27 \mathrm{~mm}$ diameter glass disc.

The BET surface area was determined on basis of the volumetric nitrogen adsorption at $\mathrm{p} / \mathrm{p}_{0}=$ $0.075,0.1$, and 0.125 at $-77.8 \mathrm{~K}$ on a Nova 1200 of the Quantachrome Corporation. 


\section{Results and discussion}

The commercial and synthesized silica gels listed in Tab. 1 show similar dissolution behaviour in the TEAOH solution. The amounts of dissolved $\mathrm{SiO}_{2}$ vary between 50 und 800 $\mathrm{mg} / \mathrm{l}$ in dependence on time and sample type for both series (Figs. 1 and 2). The dissolution rate increases thereby with the absolute rising solubility of samples.

The kinetic curves of the commercial products given in Fig. 1 show higher concentrations of dissolved $\mathrm{SiO}_{2}$ for Promeksil B12, Aerosil 200, and Sipernat 320 connected with the transformation of the solids into transparent hydrogels according to visual observation, while Silica 995and Aerosil OX 50 show lower dissolution degree, with a formation of $\mathrm{SiO}_{2}$ nanoparticles.

The curves of the synthesized gels in Fig. 2 demonstrate increasing dissolution with decreasing $\mathrm{pH}$-values of preparation. The remaining filter cakes of this series represent white gels for all the samples.

SEM micrographs of the commercial products provide the evidence that they are composed of primary particles with a significant surface roughness. In this case, particle size distribution is broad. In contrast, the synthesized samples have somewhat greater particles with a rather smooth surface. Their size lies between 10 and $910 \mu \mathrm{m}$ (Tab. 1). Selected replicas of both series are shown in Fig. 3.

As it can be seen from Tab. 1 and Fig. 3, the particle size and the crystal shape do not influence the solubility of the gels in a systematic way. The reason consists in the fact that the size distribution of the primary particles is more uniform and does not differ in less than 0.1 $\mu \mathrm{m}$ for all samples (Tab. 1).

In opposite to the values of the secondary particle size, the BET surface of samples show a systematic change and coincides with the trend in solubility. Whereas the BET values of the commercial products vary between 42 and $413 \mathrm{~m}^{2} / \mathrm{g}$, the surface of the synthesized silica gels 
ranges from 140 to $438 \mathrm{~m}^{2} / \mathrm{g}$ as shown in Tab. 1 . As evident from Figs. 1 and 2, the amount of dissolved $\mathrm{SiO}_{2}$ of the Aerosil $\mathrm{OX} 50$ and $\mathrm{SiO}_{2}(\mathrm{pH}=8)$ is consequently lowest and for Promeksil B12 and $\mathrm{SiO}_{2}(\mathrm{pH}=4)$ this parameter is observed as being highest. But in spite of the somewhat higher BET surface of the synthesized gels, their solubility does not reach higher values. For understanding of this phenomenon, the structure of the gel frameworks must be taken into consideration in more details.

The $\mathrm{Q}^{\mathrm{n}}$-group analysis on basis of the ${ }^{29} \mathrm{Si}$ MAS NMR spectroscopic measurements confirmed the dependence of the gel solubility on the state of the silica framework and, thus the structure of the internal surface. The NMR spectra of the commercial silica gels (see Fig. 4) normalized to $100 \%$ intensity show different line shape and chemical shifts of the peaks: Promeksil B12 and Sipernat 320 are characterized by different kinds of $Q^{n}$-signals. Firstly, there is $Q^{4}$ the main signal related to each $\mathrm{Si}$ atom which is linked over oxygen atoms with 4 Si neighbours. Additional signals such as $\mathrm{Q}^{3}$ and $\mathrm{Q}^{2}$ are also present in this spectrum. The first and the second are coming from $3 \mathrm{Si}$ neighbours and $1 \mathrm{OH}$-group and 2 Si neighbours and $2 \mathrm{OH}-$ groups, respectively. The chemical shift of the $Q^{4}$-peak appears at about $-110 \mathrm{ppm}$ and that of the $Q^{3}$-peaks is observed at $-100 \mathrm{ppm}$. These values of chemical shift are near to those known for cristobalite rather than to tridymite or quartz. Only the $\mathrm{Q}^{2}$-peaks strongly differ with values of $-92,4$ ppm and $-95,3$ ppm for Promeksil B12 and Sipernat 320, respectively. While the $Q^{4}-$ groups characterize network with a perfect structure consisting of $\mathrm{SiO}_{4}$-tetrahedrons, the $\mathrm{Q}^{3}-$ and $\mathrm{Q}^{2}$-groups characterize an imperfect framework responsible for the formation of chemically active hydroxyl groups. In this consequence, commercial Aerosil 200, Silica 995 and Aerosil OX 50 contain only $\mathrm{Q}^{3}$-groups related to defects in decreasing extent. However, their peak width is relative broad in comparison with crystalline silicate phases such as quartz, tridymite, and crystobalite because of non-perfect bond length and angles of their structural polyhedra. 
For all the samples except Sipernat 320, the gel solubility increases with the rising degree of defects. In contrast to Silica 995, Sipernat 320 seems to be less soluble although it contains quite more defects. The reason could be associated with a relative high content of $\mathrm{Na}_{2} \mathrm{O}$ of 2.1 weight- $\%$ (see Tab. 1) and especially contaminants of 0.15 weight- $\% \mathrm{Al}_{2} \mathrm{O}_{3}$ which remarkably reduce the amount of dissolved of $\mathrm{SiO}_{2}$. Sodium silicate and sodium aluminate which are formed under action of the TEAOH solution lead to a stronger condensation of $\left(\mathrm{SiO}_{2}\right)_{\mathrm{n}}$ units over -Si-O-Al-O-Si- bonds. Sipernat 320 produces, therefore, more hydrogel gel than Aerosil 200 and Promeksil B12.

As evident from Fig. 5, ${ }^{29} \mathrm{Si}$ MAS NMR spectra of the synthesized samples show $\mathrm{Q}^{4}$-groups as well as $\mathrm{Q}^{3}$ and $\mathrm{Q}^{2}$-groups. The corresponding signals are centred at similar chemical shifts of about $-111 \mathrm{ppm}\left(\mathrm{Q}^{4}\right),-101 \mathrm{ppm}\left(\mathrm{Q}^{3}\right)$, and $-92-93 \mathrm{ppm}\left(\mathrm{Q}^{2}\right)$ as in the case of commercial products. But the line width of the signals observed are smaller. This could give a hint to the higher regularity in respect to the bond length and angle. This may compensate the greater number of defects which affect the dissolution behaviour, therefore the solubility becomes smaller than expected from the BET surface values.

IR spectroscopic measurements give also a direct hint to the state of the $\mathrm{SiO}_{2}$ framework. For two selected samples, typical spectra are shown in Fig. 6. One could recognise peaks for the tetrahedron, the symmetrical TOT valence, and the asymmetrical TOT valence vibration in the range of wave numbers of $467-478 \mathrm{~cm}^{-1}, 802-812 \mathrm{~cm}^{-1}$, and $1082-1121 \mathrm{~cm}^{-1}$, respectively. Particularly, the asymmetrical TOT $(\mathrm{T}=\mathrm{Si})$ valence vibration shifts significantly to lower $\mathrm{w}_{\mathrm{TOT}}$ values with a raising number of the framework defects as it is shown in Tab. 1.

This effect was extensively investigated for aluminosilicate zeolites, e.g. of the Y type [16, 17]. With change in the content of framework aluminium in $\mathrm{Si} / \mathrm{Al}$ ratios from 2.4 to 139 , $\mathrm{w}_{\text {TOT }}$ peak shifts from 1019 to $1082 \mathrm{~cm}^{-1}$ [18]. The reason could be in more regular bond angles when aluminium content is decreased owing to different bond length of the Al-O and the Si-O 
units with 173 pm and 163 pm, respectively. A pure $\mathrm{SiO}_{2}$ framework needs therefore higher activation energy for the vibrations which reflects in a higher wave number during IR spectroscopic measurements.

Although silica gels practically do not contain aluminium atoms, the shift of the TOT valence vibration depends also on the different bond length and angle in $\mathrm{Si}(\mathrm{OSi})_{4}, \mathrm{Si}(\mathrm{OSi})_{3}(\mathrm{OH})$ or $\mathrm{Si}(\mathrm{OSi})_{2}(\mathrm{OH})_{2}$ tetrahedra. In contrast to the synthesized samples, the $\mathrm{w}_{\text {TOT }}$ values of the commercial silica gels are generally sligthly higher and differ, with values ranging from 1101 to $1120 \mathrm{~cm}^{-1}$ against values lying between 1082 and $1105 \mathrm{~cm}^{-1}$. It means that commercial products have low degree of defects which fits nicely with data obtained by the ${ }^{29} \mathrm{Si}$ MAS NMR spectra. This is the reason why Aerosil OX 50 or $\mathrm{SiO}_{2}(\mathrm{pH}=8)$ needs the highest and Promeksil $\mathrm{B} 12$ and $\mathrm{SiO}_{2}(\mathrm{pH}=2)$ the lowest activation energies corresponding to the highest and the lowest IR wave numbers for each series as seen from Tab. 1. The solubility of the samples increases in the same tendency.

In the series of synthesized silica gels, a specific observation lies in the fact that the saturation

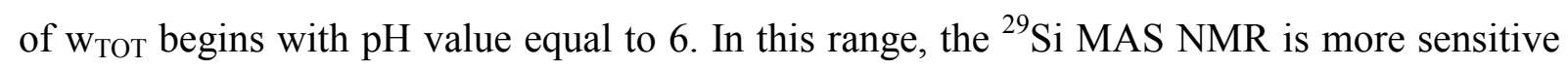
than the IR spectroscopy. Nevertheless, synthesized silica gel products could be characterized by IR spectroscopic measurements with a high sensitivity over a wide range, too. 


\section{Conclusion}

The solubility of silica gels in TEAOH solution depends on the internal BET surface of samples. In opposite to crystalline porous silicates such as zeolites, the surface of silica gels with irregular pore system contains, in addition to $\mathrm{Si}(\mathrm{OSi})_{4}\left(\mathrm{Q}^{4}\right), \mathrm{Si}(\mathrm{OSi})_{3} \mathrm{OH}\left(\mathrm{Q}^{3}\right)$ and $\mathrm{Si}(\mathrm{OSi})_{2}(\mathrm{OH})_{2}\left(\mathrm{Q}^{2}\right)$ structure units. The more the $\mathrm{SiO}_{2}$ framework is disturbed, the stronger hydroxide ions of the TEAOH solution attack the silica framework at the terminal OH groups. In the case of commercial products, manufacturing process affects the formation of structural defects and cannot be exactly estimated. In the case of silica gels which were obtained from precipitation on basis of water glass solution (synthesized samples), it was observed that the number of defects increases with decreasing the $\mathrm{pH}$ value during precipitation process.

The $Q^{n}$ group analysis of the silica gels was successfully employed with the help of ${ }^{29}$ Si MAS NMR measurements. It appeared also that IR spectroscopic analysis could help with the reliable characterization of the structure under special consideration. In this case, the asymmetrical TOT valence vibration of the $\mathrm{SiO}_{2}$ framework shifts sensitively to lower wave numbers with the raising degree of defects.

The shape of the secondary silica gel particles, characterized by SEM, does not influence the dissolution systematically. Different residual filter cakes such as white solids, transparent hydro-gels, and silica nano-particles can be observed. The contamination of the silica gel by traces of aluminium compounds leads to the increased formation of a secondary gel phase due to precipitation of the secondary $(\mathrm{SiO})_{\mathrm{n}}$ particles containing -Si-O-Al-O-Si- bonds. 


\section{References}

[1] D.W. Breck, Zeolite Molecular Sieves, John Wiley \& Sons, London 1974.

[2] R. Barrer, Hydrothermal Chemistry of Zeolites, Academic Press, London, 1982.

[3] Chromatographie

[4] C. Mc Donagh, P. Bowe, K. Mongey, B. D. Mac Craith, J. Non-Cryst. Solids, 2002, $306,138$.

[5] A.O. Dieng, R.Z. Wang, Renew. Sustainable Energy Rev., 2001, 5, 313.

[6] E. H. Hauser, Silicic Science, Van Nostrand, Princeton, 1955.

[7] R. B. Sosman, The Phase of Silica, Rutgers University Press, New Brunswick, 1965.

[8] W. Hinz, Silicate: Grundlagen der Silicatwissenschaft und Silicattechnik, Vol. 2, Verlag Bauwesen, Berlin, 1971.

[9] R.K. Iler, The chemistry of silica, Wiley \& Sons, New York, 1979.

[10] G. Engelhardt, D. Michel, High Resolution Solid State NMR of Silicates and Zeolites, Wiley \& Sons, New York, 1987.

[11] C. Cannas, M. Casu, A. Musinu, G. Piccaluga, J. Non-Cryst. Solids, 2005, 351, 3476.

[12] J. Estella, J. C. Echeverria, M. Laguna, J. Garrido, Microp. Mesopor. Mater., 2007, $102,274$.

[13] A. Fidalgo, L. M. Ilharco, Microp. Mesopor. Mater., 2005, 84, 229.

[14] S.P. Zhdanov, S.S. Chvoshchev, N.N. Samulevich, Synthesized Zeolites, Gordon \& Breach Science Publishers, New York, 1990.

[15] D. Massiot, F. Fayon, M. Capron, I. King, S. Le Calvé, B. Alonso, J.O. Durand,

B. Bujoli, Z. Gan, G. Hoatson, Magn. Reson. Chem. 40 (2002) 70 - 76

[16] E. M. Flanigen, in Zeolite Chem. Catal. Ed. J. A. Rabo, ACS Monographs 171 (1976) 81 .

[17] H. Fichtner-Schmittler, U. Lohse, H. Miessner, H. E. Maneck, Z. Phys. Chem. 
Leipzig 271 (1990) 69.

[18] C. H. Rüscher, J.-Chr. Buhl, W. Lutz, in A. Galarneau, F. Di Renzo, F. Fajula, and

J. Vedrine (Eds.), Stud. Surf. Sci. Cat., Vol. 135, Elsevier, Amsterdam, 2001, 13-P15, p. 1. 
Table 1

\begin{tabular}{|l|c|c|c|c|}
\hline \multicolumn{1}{|c|}{$\begin{array}{c}\text { sample } \\
\text { denotation }\end{array}$} & $\begin{array}{c}\text { sample } \\
\text { type }\end{array}$ & $\begin{array}{c}\text { particle size } \\
\mu \mathrm{m} \\
\text { secondary/primary }\end{array}$ & $\begin{array}{c}\text { BET surface } \\
\mathrm{m}^{2} / \mathrm{g}\end{array}$ & $\begin{array}{c}\text { IR } v_{\mathrm{TOT}}, \\
\mathrm{cm}^{-1}\end{array}$ \\
\hline \multicolumn{5}{|c|}{ commercial silica gels } \\
\hline Promeksil B12 & precipitated & $<10 /<0.08$ & 413 & 1101 \\
\hline Sipernat 320 & precipitated & $<75 /<0.06$ & 196 & 1107 \\
\hline Aerosil 200 & pyrogene & $<310 /<0.09$ & 210 & 1110 \\
\hline Silica 995 & pyrogene & $<28 /<0.07$ & 61 & 1117 \\
\hline Aerosil OX 50 & pyrogene & $<34 /<0.09$ & 42 & 1120 \\
\hline \multicolumn{5}{|c|}{ synthesized silica gels } \\
\hline $\mathrm{SiO}_{2}(\mathrm{pH} \mathrm{2)}$ & precipitated & $<380 /<0.12$ & 538 & 1082 \\
\hline $\mathrm{SiO}_{2}(\mathrm{pH} \mathrm{3)}$ & precipitated & $<283 /<0.08$ & 513 & 1088 \\
\hline $\mathrm{SiO}_{2}(\mathrm{pH} \mathrm{4)}$ & precipitated & $<103 /<0.09$ & 507 & 1095 \\
\hline $\mathrm{SiO}_{2}(\mathrm{pH} \mathrm{5)}$ & precipitated & $<94 /<0.03$ & 404 & 1101 \\
\hline $\mathrm{SiO}_{2}(\mathrm{pH} \mathrm{6)}$ & precipitated & $<112 /<0.06$ & 352 & 1105 \\
\hline $\mathrm{SiO}_{2}(\mathrm{pH} \mathrm{7)}$ & precipitated & $<910 /<0.04$ & 172 & 1103 \\
\hline $\mathrm{SiO}_{2}(\mathrm{pH} \mathrm{8)}$ & precipitated & $<113 /<0.06$ & 140 & 1105 \\
\hline
\end{tabular}


Fig. 1 Alkaline solubility of commercial silica gels

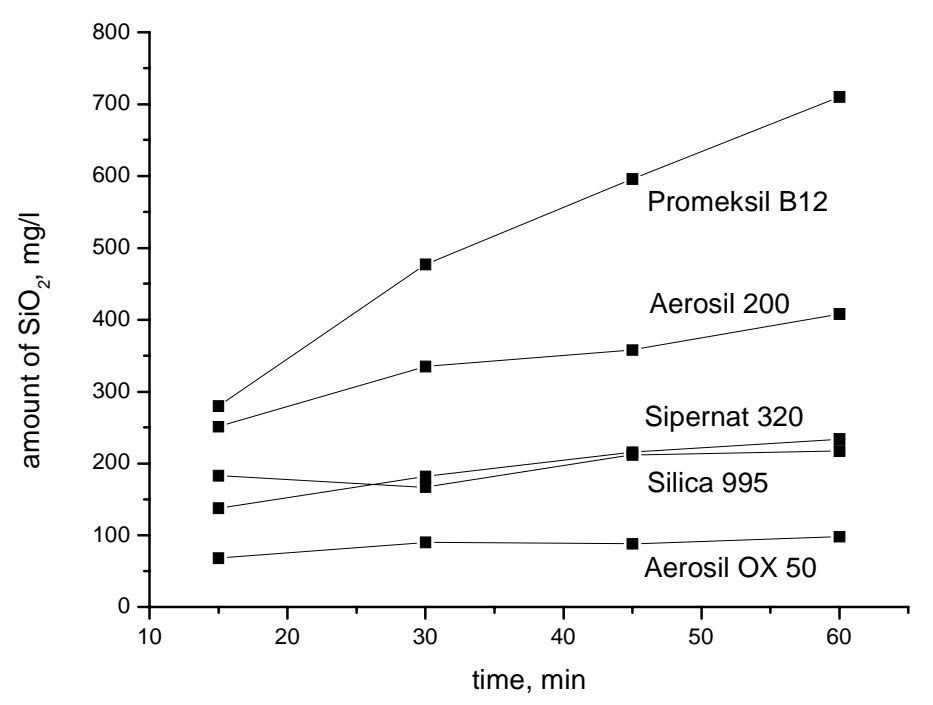


Fig. 2 Alkaline solubility of synthesized silica gels

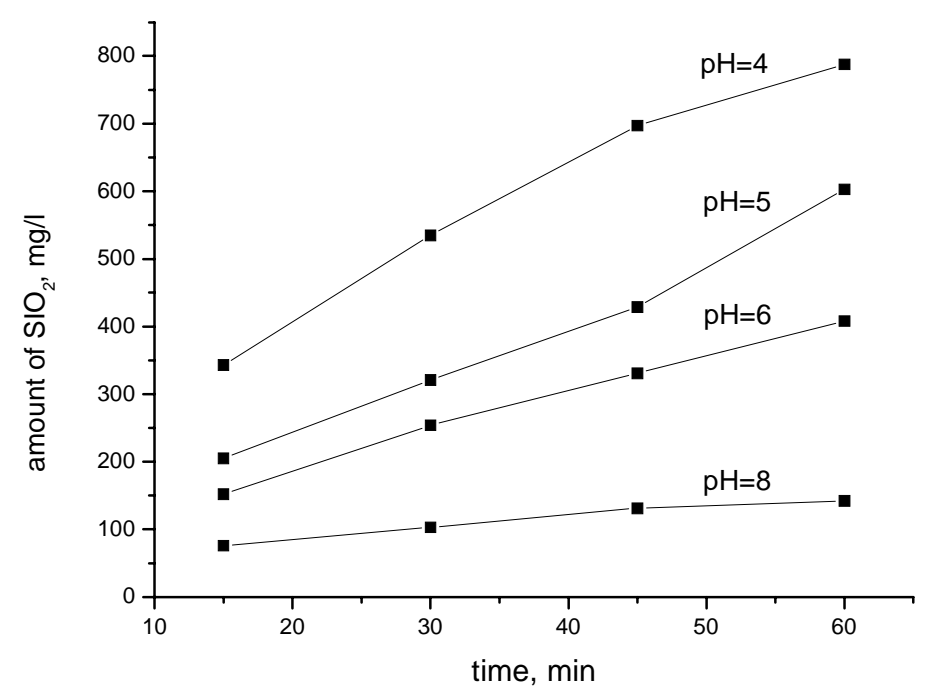


Fig. 3 Scanning electron micrographs of Aerosil $200(a, b)$ and synthesized silica gel precipitated at $\mathrm{pH}=2$

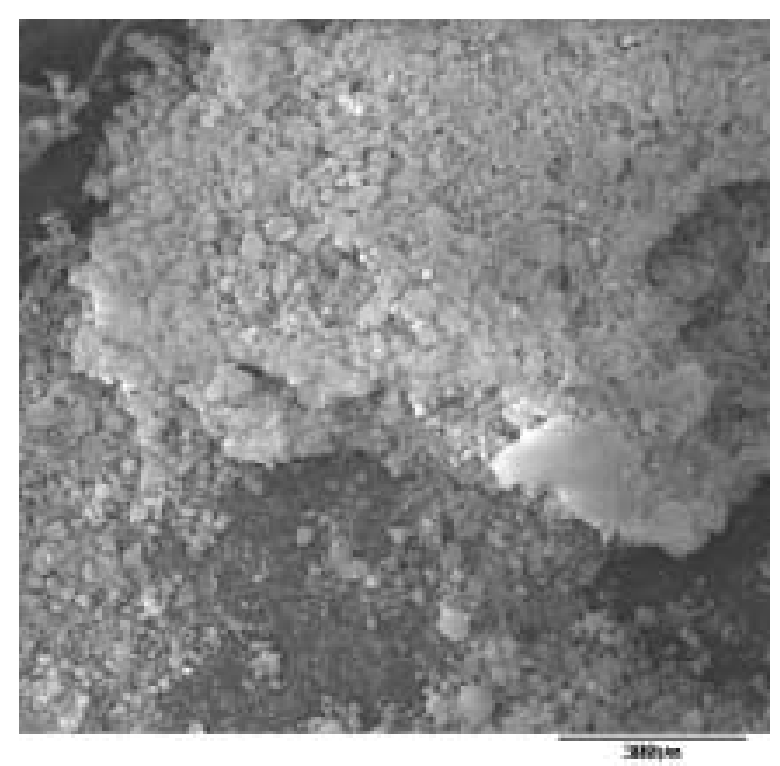

(a)

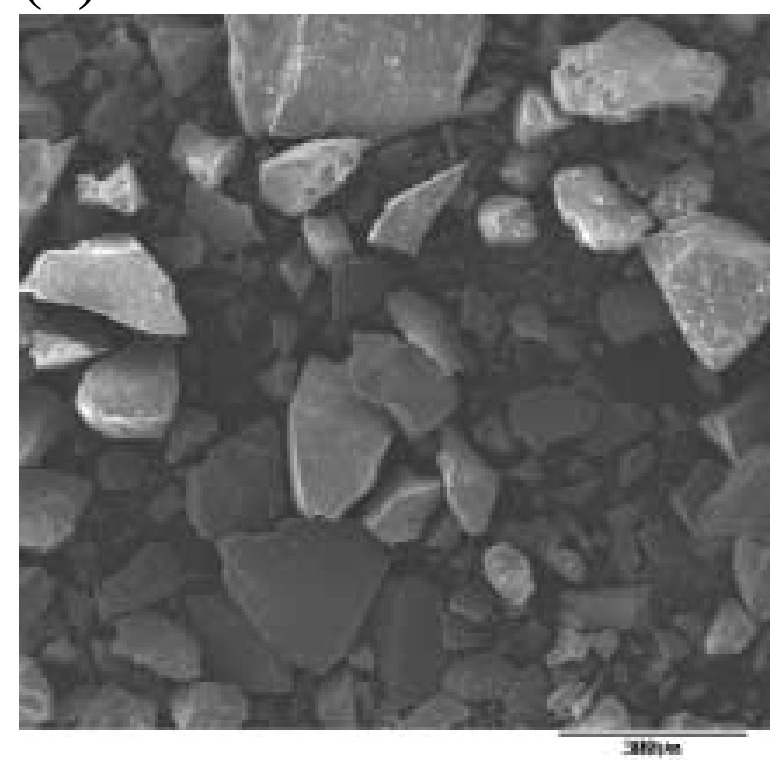

(c)

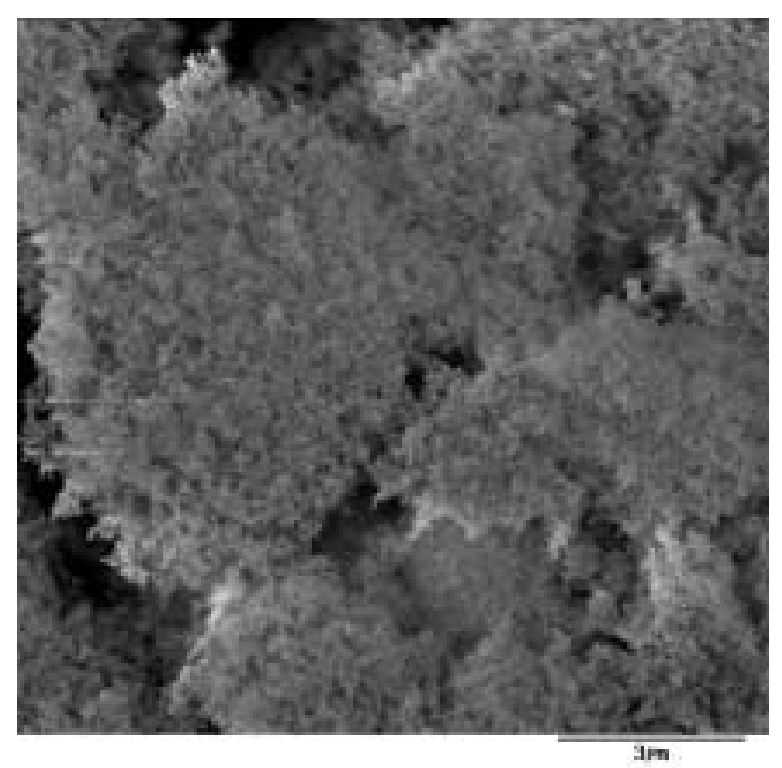

(b)

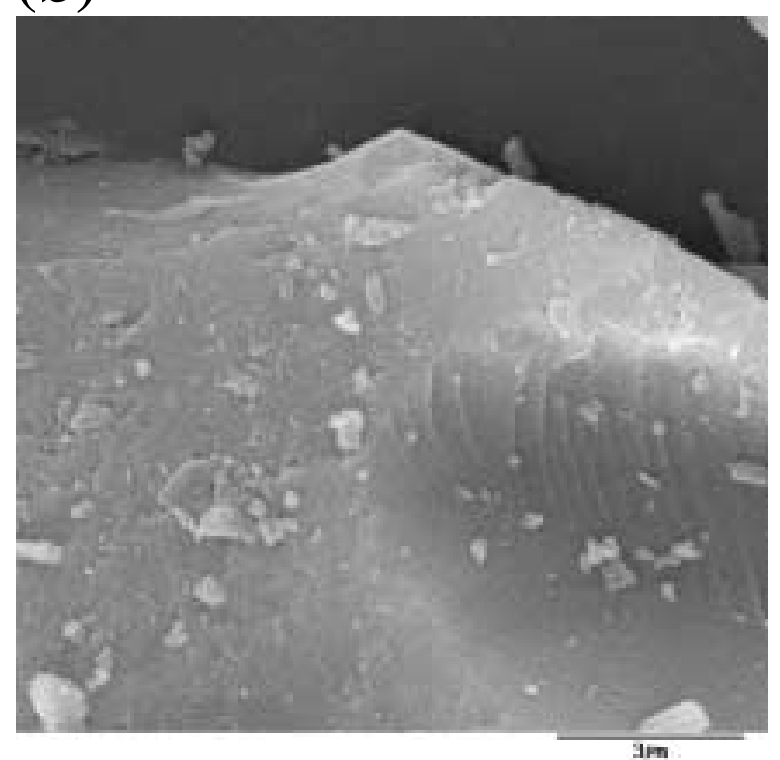

(d) 
Abb. $4 \quad{ }^{29}$ Si MAS NMR spectra of the commercial silica gels

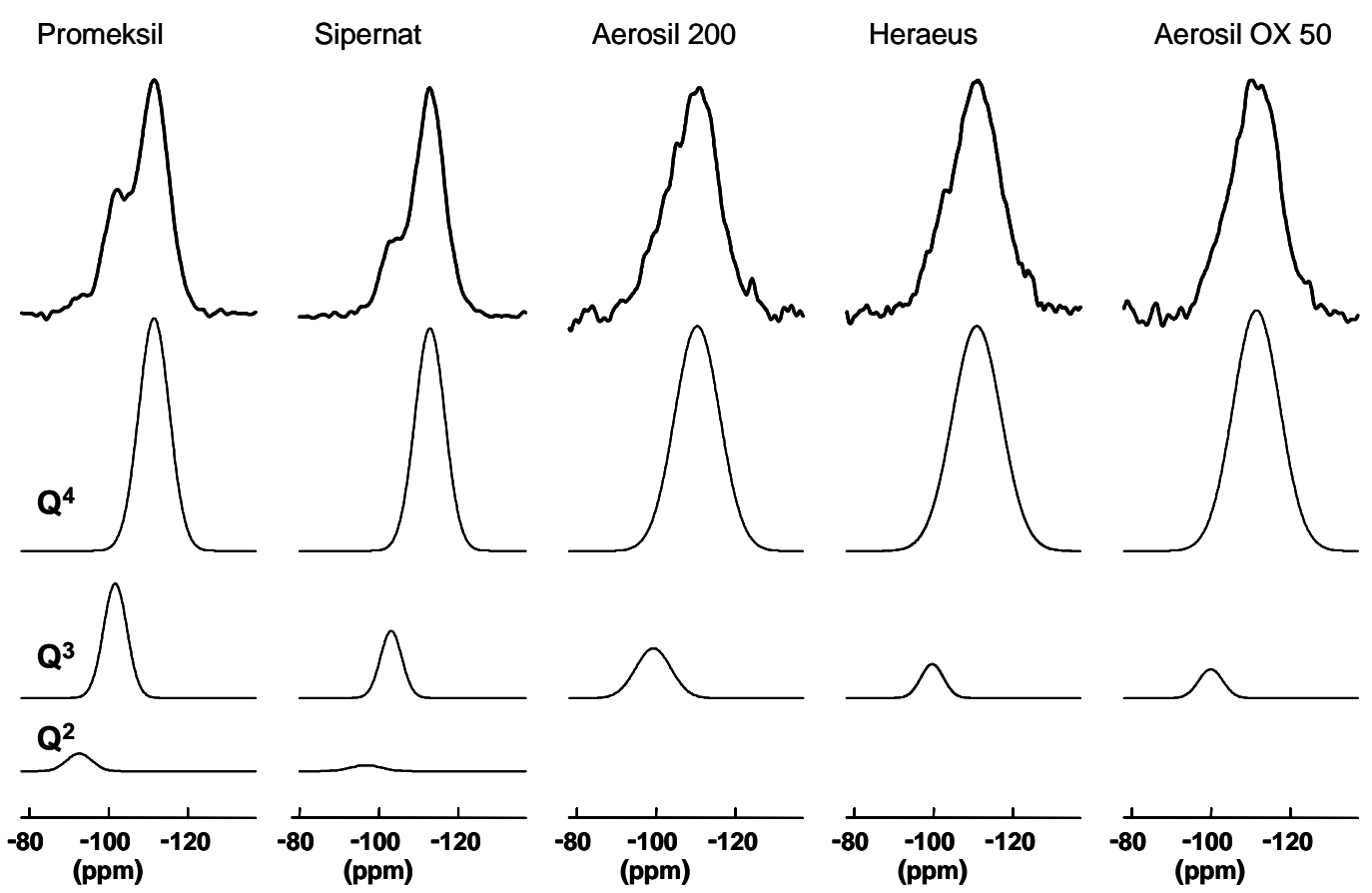


Abb. $5 \quad{ }^{29} \mathrm{Si}$ MAS NMR spectra of the synthesized silica gels in dependence of the $\mathrm{pH}$ value
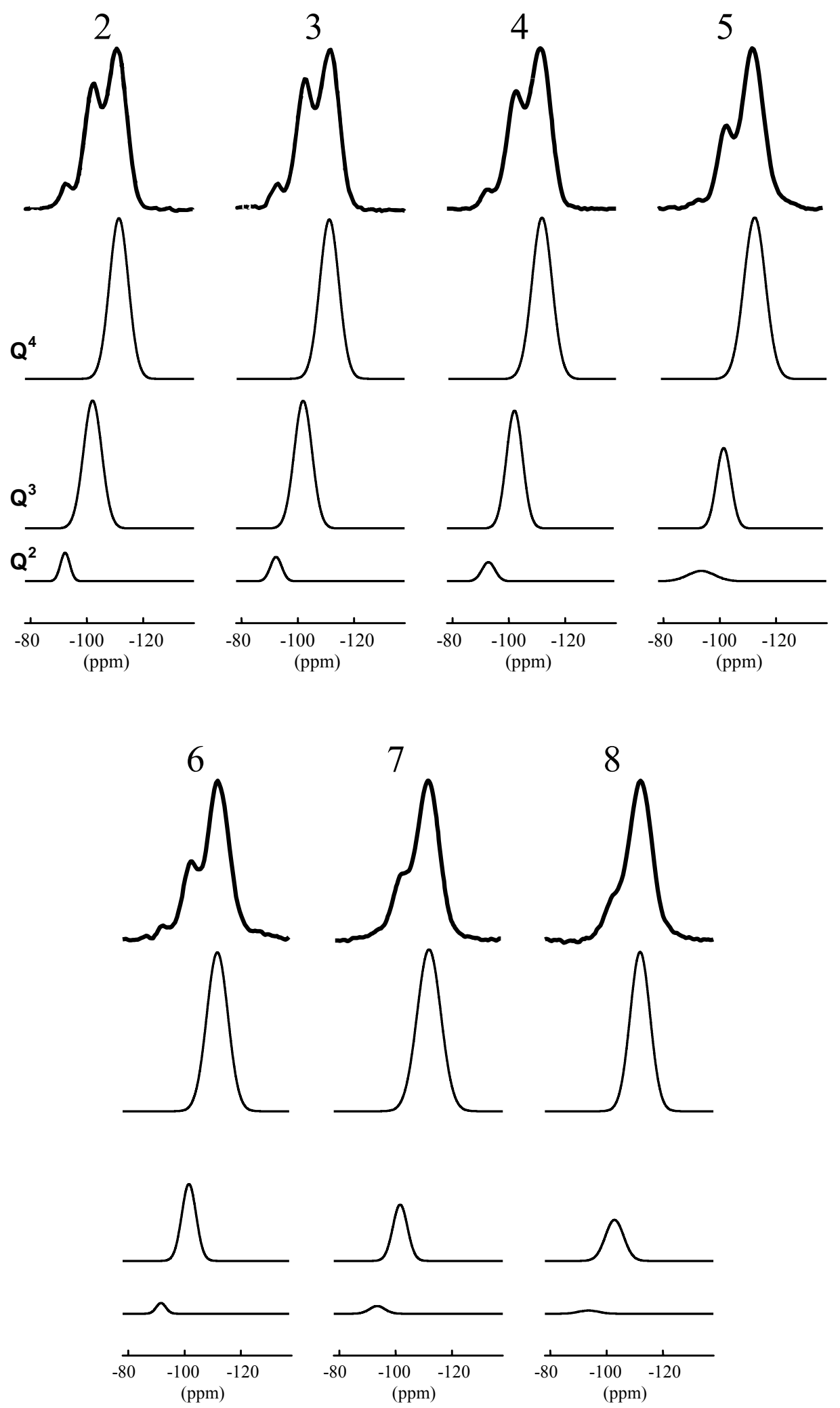
Abb. 6 IR spectra of selected commercial and synthesized silica gels

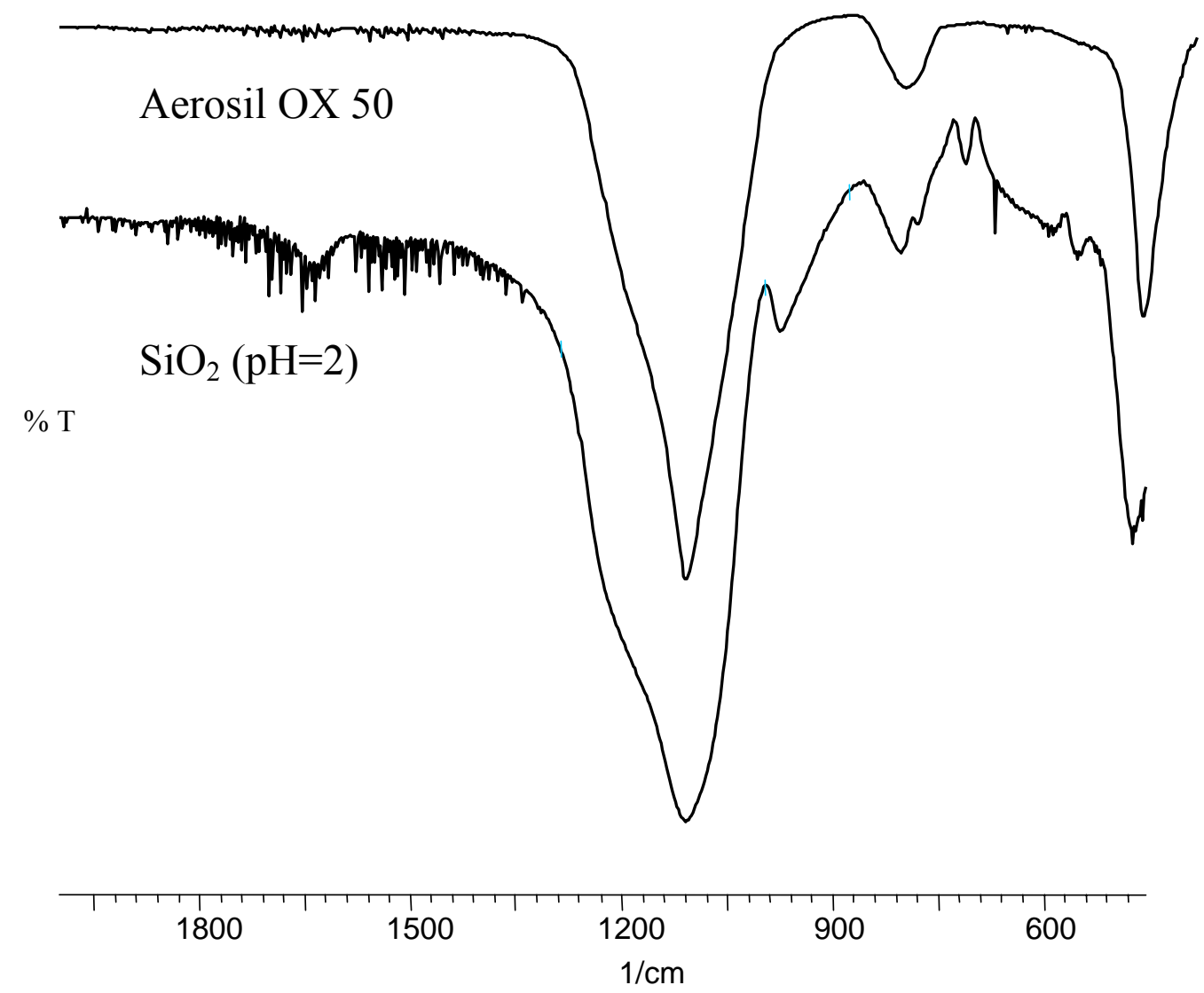




\title{
Characterization of Silica gels by ${ }^{29} \mathrm{Si}$ MAS NMR and IR Spectroscopic
}

\section{Measurements}

W. Lutz ${ }^{*}$, D. Täschner, R. Kurzhals, ${ }^{\mathrm{a} D}$. Heidemann, ${ }^{\mathrm{b}}$ C. Hübert, Berlin and Bitterfeld, Süd-Chemie Zeolites GmbH, ${ }^{\mathrm{a} B e r l i n, ~ H u m b o l d t-U n i v e r s i t a ̈ t ~ z u ~ B e r l i n ~}$

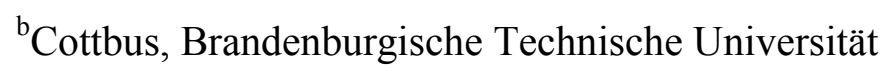

Received ........

\begin{abstract}
The solubility of commercial and synthesized silica gels in a solution of Tetra-EthylAmmonium-Hydroxide (TEAOH) was investigated at room temperature. The state of parent silica frameworks was characterized by BET and SEM. The structural defects were identified both by the $\mathrm{Q}^{\mathrm{n}}$ group analysis in ${ }^{29} \mathrm{Si}$ MAS NMR and IR spectroscopic investigation. It was found that the dissolution rate of the samples shows a tendency for growing up with an increasing BET surface. The increase of the internal surface was accompanied by formation of $\mathrm{Si}(\mathrm{OSi})_{3}(\mathrm{OH})\left(\mathrm{Q}^{3}\right)$ and $\mathrm{Si}(\mathrm{OSi})_{2}(\mathrm{OH})_{2}\left(\mathrm{Q}^{2}\right)$ structural units. The higher the number of $\mathrm{Q}^{3}$ and $\mathrm{Q}^{2}$ groups observed, the faster the samples were dissolved in TEAOH solution due to the attack of the hydroxide ions on the terminal $\mathrm{OH}$ groups of the framework. The asymmetrical TOT valence vibration of the IR spectra was systematically shifted to lower values with increase in the number of $\mathrm{Q}^{3}$ and $\mathrm{Q}^{2}$ structure groups.
\end{abstract}


Keywords: silicates, solid state structure, solvent effects, NMR spectroscopy, IR spectroscopy

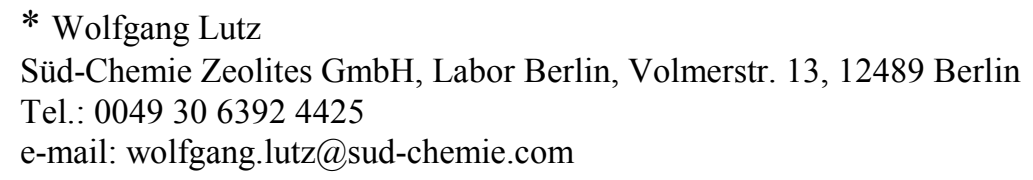

Charakterisierung von Silicagelen mit Hilfe der IR- and ${ }^{29}$ Si MAS NMR-

Spektroskopie

\section{Inhaltsübersicht.}

Die Löslichkeit kommerzieller Silicagele und Gele eigener Herstellung in TEAOH-Lösung wurde bei Raumtemperatur untersucht. Die Löslichkeit stieg mit zunehmender Zahl von Strukturdefekten in der $\mathrm{SiO}_{2}$-Matrix, die mit Hilfe der $\mathrm{Q}^{\mathrm{n}}$-Gruppen-Analyse aus ${ }^{29} \mathrm{Si}$ MAS NMR-Spektren charakterisiert wurden. Die Wellenzahl der asymmetrische TOT $(\mathrm{T}=\mathrm{Si})$ Valenzschwingung in IR-Spektren verschob sich mit Zunahme der Strukturdefekte systematisch zu niedrigeren Werten. 


\section{$1 \quad$ Introduction}

Silica gels have been used in the chemical industry and laboratory technique as drying agents [1], feed stock of zeolite synthesis [2], and separation medium in chromatography [3] for a long period. More recently, they were applied also as wafer of optical sensors [4] and for heat storage by water sorption [5]. Pioneers reporting the physical and chemical properties of silica gels are Hauser [6], Sosman [7], or Hinz [8]. A general view about "The chemistry of silica" was published in 1979 by Iler [9].

Engelhardt and Michel [10] characterized the framework of silica gels by the $\mathrm{Q}^{\mathrm{n}}$ group analysis $\left(\mathrm{n}=\right.$ number of bridging oxygen atoms in the $\mathrm{SiO}_{4}$-tetrahedron under study) and Cannes [11] reported on the surface properties by the characterization of silanol groups by means of ${ }^{29}$ Si MAS NMR and CP MAS NMR experiments. IR spectroscopic measurements gave information about surface $\mathrm{OH}$-groups $[11,12]$ and the $\mathrm{SiO}_{2}$ framework [13].

The application of silica gels for the synthesis of zeolites was described in detail by Breck [1], Barrer [2], and Zhdanov [14]. The synthesis process of these aluminosilicates follows quite different recipes. The particle size, size distribution, and shape of the crystals obtained are decisively determined by the crystallization kinetics. All parameters depend on the temperature, alkalinity and composition of the synthesis batch, and, finally, the type of silica source. While in the classical synthesis of 4A (LTA) and X (FAU) zeolites water glass solution is used as silicate component, the synthesis of zeolites beta (BEA), mordenite (MOR), or ZSM-5 (MFI) involves the silica gels.

The reactivity of silica gels depends on their solubility in the alkaline mother liquors of the synthesis batches. Mechanism, kinetics and, consequently, the quality of the final products are thereby influenced by the size of $\mathrm{SiO}_{2}$ particles as well as by the condensation state of the $\mathrm{SiO}_{2}$ network. The crystal shape can be characterized by the scanning electron microscopic 
investigation (SEM) and the solubility by chemical analysis of the liquid phase. ${ }^{29} \mathrm{Si}$ MAS NMR and IR measurements can give direct hints to the state of the $\mathrm{SiO}_{2}$ framework.

This paper is aimed to demonstrate the applicability of the ${ }^{29} \mathrm{Si}$ MAS NMR as well as the IR spectroscopy as suitable methods for the efficient characterization of the framework state of silica gels, using two differently prepared sample series. 


\section{$2 \quad$ Results}

The commercial and synthesized silica gels listed in Tab. 1 show similar dissolution behaviour in the TEAOH solution. The amounts of dissolved $\mathrm{SiO}_{2}$ vary between 50 und 800 $\mathrm{mg} / \mathrm{l}$ in dependence on time and sample type for both series (Figs. 1 and 2). The dissolution rate increases thereby with the absolute rising solubility of samples.

The kinetic curves of the commercial products given in Fig. 1 show higher concentrations of dissolved $\mathrm{SiO}_{2}$ for Promeksil B12, Aerosil 200, and Sipernat 320 connected with the transformation of the solids into transparent hydrogels according to visual observation, while Silica 995and Aerosil OX 50 show lower dissolution degree, with a formation of $\mathrm{SiO}_{2}$ nanoparticles.

The curves of the synthesized gels in Fig. 2 demonstrate increasing dissolution with decreasing $\mathrm{pH}$-values of preparation. The remaining filter cakes of this series represent white gels for all the samples.

SEM micrographs of the commercial products provide the evidence that they are composed of primary particles with a significant surface roughness. In this case, particle size distribution is broad. In contrast, the synthesized samples have somewhat greater particles with a rather smooth surface. Their size lies between 10 and $910 \mu \mathrm{m}$ (Tab. 1). Selected replicas of both series with the typical different particle habit are shown in Fig. 3.

In opposite to the values of the particle size which does not influence the solubility of the gels in a systematic way as can be seen from Tab. 1 and Figs. 1 and 2, the BET surface of samples show a systematic change and coincides with the trend in solubility. Whereas the BET values of the commercial products vary between 42 and $413 \mathrm{~m}^{2} / \mathrm{g}$, the surface of the synthesized silica gels ranges from 140 to $438 \mathrm{~m}^{2} / \mathrm{g}$ (in dependence also of sample milling). As evident from Figs. 1 and 2, the amount of dissolved $\mathrm{SiO}_{2}$ of the Aerosil $\mathrm{OX} 50$ and $\mathrm{SiO}_{2}(\mathrm{pH}=8)$ is consequently lowest and for Promeksil $\mathrm{B} 12$ and $\mathrm{SiO}_{2}(\mathrm{pH}=4)$ this parameter is observed as 
being highest. Figs. 4 and 5 demonstrate this tendency by the dependence of the solubility on the BET surface of samples. But in spite of the somewhat higher BET surface of the synthesized gels, their solubility does not reach systematically higher values. For understanding of this phenomenon, the structure of the gel frameworks must be taken into consideration in more details.

The $\mathrm{Q}^{\mathrm{n}}$-group analysis on basis of the ${ }^{29} \mathrm{Si}$ MAS NMR spectroscopic measurements confirmed the dependence of the gel solubility on the state of the silica framework and, thus, the structure of the internal surface. The NMR spectra of the commercial silica gels in Fig. 6 normalized to $100 \%$ intensity show different line shapes and chemical shifts of the peaks: Promeksil B12 and Sipernat 320 are characterized by different kinds of $\mathrm{Q}^{\mathrm{n}}$-signals. Firstly, there is $\mathrm{Q}^{4}$ the main signal related to each $\mathrm{Si}$ atom which is linked over oxygen atoms with 4 Si neighbours. Additional signals such as $\mathrm{Q}^{3}$ and $\mathrm{Q}^{2}$ are also present in this spectrum. The first and the second are coming from $3 \mathrm{Si}$ neighbours and $1 \mathrm{OH}$-group and $2 \mathrm{Si}$ neighbours and 2 OH-groups, respectively. The chemical shift of the $Q^{4}$-peak appears at about $-110 \mathrm{ppm}$ and that of the $Q^{3}$-peaks is observed at $-100 \mathrm{ppm}$. These values of chemical shift are near to those known for cristobalite rather than to tridymite or quartz. Only the $\mathrm{Q}^{2}$-peaks strongly differ with values of $-92,4$ ppm and $-95,3$ ppm for Promeksil B12 and Sipernat 320, respectively. While the $\mathrm{Q}^{4}$-groups characterize network with a perfect structure consisting of $\mathrm{SiO}_{4}$ tetrahedrons, the $\mathrm{Q}^{3}$ - and $\mathrm{Q}^{2}$-groups characterize an imperfect framework responsible for the formation of chemically active hydroxyl groups. In this consequence, commercial Aerosil 200, Silica 995 and Aerosil OX 50 contain only $\mathrm{Q}^{3}$-groups related to defects in decreasing extent. However, their peak width is relative broad in comparison with crystalline silicate phases such as quartz, tridymite, and crystobalite because of non-perfect bond length and angles of their structural polyhedra. A quantification of the volume fraction of all Q-groups is shown in Tab. 1. 
For all the samples except Sipernat 320, the gel solubility increases with the rising degree of defects. In contrast to Silica 995, Sipernat 320 seems to be less soluble although it contains quite more defects. The reason could be associated with a relative high content of $\mathrm{Na}_{2} \mathrm{O}$ of 2.1 weight- $\%$ (see Tab. 1) and especially contaminants of 0.15 weight- $\% \mathrm{Al}_{2} \mathrm{O}_{3}$ which remarkably reduce the amount of dissolved of $\mathrm{SiO}_{2}$. Sodium silicate and sodium aluminate which are formed under action of the TEAOH solution lead to a stronger condensation of $\left(\mathrm{SiO}_{2}\right)_{\mathrm{n}}$ units over -Si-O-Al-O-Si- bonds. Sipernat 320 produces, therefore, more hydrogel gel than Aerosil 200 and Promeksil B12.

As evident from Fig. 76, ${ }^{29} \mathrm{Si}$ MAS NMR spectra of the synthesized samples show $\mathrm{Q}^{4}$-groups as well as $\mathrm{Q}^{3}$ and $\mathrm{Q}^{2}$-groups. The corresponding signals are centred at similar chemical shifts of about $-111 \mathrm{ppm}\left(\mathrm{Q}^{4}\right),-101 \mathrm{ppm}\left(\mathrm{Q}^{3}\right)$, and -92 to $-93 \mathrm{ppm}\left(\mathrm{Q}^{2}\right)$ as in the case of commercial products. But the line width of the signals observed are smaller. This could give a hint to the higher regularity in respect to the bond length and angle. This may compensate the greater number of defects which affect the dissolution behaviour, therefore the solubility becomes smaller than expected from the BET surface values.

IR spectroscopic measurements give also a direct hint to the state of the $\mathrm{SiO}_{2}$ framework. For two selected samples, typical spectra are shown in Fig. 8. One could recognise peaks for the tetrahedron, the symmetrical TOT valence, and the asymmetrical TOT valence vibration in the range of wave numbers of 467 to $478 \mathrm{~cm}^{-1}, 802$ to $812 \mathrm{~cm}^{-1}$, and 1082 to $1121 \mathrm{~cm}^{-1}$, respectively. Particularly, the asymmetrical TOT $(\mathrm{T}=\mathrm{Si})$ valence vibration shifts significantly to lower $\mathrm{w}_{\text {Tот }}$ values with a raising number of the framework defects as it is shown in Tab. 1 . This effect was extensively investigated for aluminosilicate zeolites, e.g. of the Y type [16, 17]. With change in the content of framework aluminium in $\mathrm{Si} / \mathrm{Al}$ ratios from 2.4 to 139 , $\mathrm{w}_{\mathrm{TOT}}$ peak shifts from 1019 to $1082 \mathrm{~cm}^{-1}$ [18]. The reason could be in more regular bond angles when aluminium content is decreased owing to different bond length of the Al-O and the Si-O 
units with 173 pm and 163 pm, respectively. A pure $\mathrm{SiO}_{2}$ framework needs therefore higher activation energy for the vibrations which reflects in a higher wave number during IR spectroscopic measurements.

Although silica gels practically do not contain aluminium atoms, the shift of the TOT valence vibration depends also on the different bond length and angle in $\mathrm{Si}(\mathrm{OSi})_{4}, \mathrm{Si}(\mathrm{OSi})_{3}(\mathrm{OH})$ or $\mathrm{Si}(\mathrm{OSi})_{2}(\mathrm{OH})_{2}$ tetrahedra. In contrast to the synthesized samples, the $\mathrm{w}_{\text {TOT }}$ values of the commercial silica gels are generally sligthly higher and differ, with values ranging from 1101 to $1120 \mathrm{~cm}^{-1}$ against values lying between 1082 and $1105 \mathrm{~cm}^{-1}$. Taking into consideration a sensitivity of the signals of $\pm 1 \mathrm{~cm}^{-1}$ for the commercial as well as synthesized silica gels significant changes in their structure can be observed. The results mean that commercial products have low degree of defects which fits nicely with data obtained by the ${ }^{29} \mathrm{Si}$ MAS NMR spectra. This is the reason why Aerosil OX 50 or $\mathrm{SiO}_{2}(\mathrm{pH}=8)$ needs the highest and Promeksil $\mathrm{B} 12$ and $\mathrm{SiO}_{2}(\mathrm{pH}=2)$ the lowest activation energies corresponding to the highest and the lowest IR wave numbers for each series as seen from Tab. 1. The solubility of the samples increases in the same tendency.

In the series of synthesized silica gels, a specific observation lies in the fact that the saturation of $\mathrm{w}_{\text {TOT }}$ begins with $\mathrm{pH}$ value equal to 6 . In this range, the ${ }^{29} \mathrm{Si}$ MAS NMR is more sensitive than the IR spectroscopy. Nevertheless, synthesized silica gel products could be characterized by IR spectroscopic measurements with a high sensitivity over a wide range, too. 


\section{Discussion}

The solubility of silica gels in TEAOH solution depends on the internal BET surface of samples. In opposite to crystalline porous silicates such as zeolites, the surface of silica gels with irregular pore system contains, in addition to $\mathrm{Si}(\mathrm{OSi})_{4}\left(\mathrm{Q}^{4}\right), \mathrm{Si}(\mathrm{OSi})_{3} \mathrm{OH}\left(\mathrm{Q}^{3}\right)$ and $\mathrm{Si}(\mathrm{OSi})_{2}(\mathrm{OH})_{2}\left(\mathrm{Q}^{2}\right)$ structure units. The more the $\mathrm{SiO}_{2}$ framework is disturbed, the stronger hydroxide ions of the TEAOH solution attack the silica framework at the terminal OH groups. In the case of commercial products, manufacturing process affects the formation of structural defects and cannot be exactly estimated. In the case of silica gels which were obtained from precipitation on basis of water glass solution (synthesized samples), it was observed that the number of defects increases with decreasing the $\mathrm{pH}$ value during precipitation process.

The $Q^{n}$ group analysis of the silica gels was successfully employed with the help of ${ }^{29}$ Si MAS NMR measurements. It appeared also that IR spectroscopic analysis could help with the reliable characterization of the structure under special consideration. In this case, the asymmetrical TOT valence vibration of the $\mathrm{SiO}_{2}$ framework shifts sensitively to lower wave numbers with the raising degree of defects.

The shape of the secondary silica gel particles, characterized by SEM, does not influence the dissolution systematically. Different residual filter cakes such as white solids, transparent hydro-gels, and silica nano-particles can be observed. The contamination of the silica gel by traces of aluminium compounds leads to the increased formation of a secondary gel phase due to precipitation of the secondary $(\mathrm{SiO})_{\mathrm{n}}$ particles containing $-\mathrm{Si}-\mathrm{O}-\mathrm{Al}-\mathrm{O}-\mathrm{Si}$ - bonds. 


\section{Experimental Part}

\section{Materials}

Commercial silica gels used for different zeolite synthesis processes and shown in Tab. 1 as well as synthesized silica gels were investigated. The latter were prepared according to the following route. The aqueous solution of sodium silicate was transformed into acid silica sol using "Wofatit KPS 200" as ion exchanger resin. $220 \mathrm{ml}$ silicate solution (1.8 $\mathrm{M}$ in $\left.\mathrm{SiO}_{2}\right)$ was dropped into a stirred batch of $1000 \mathrm{ml}$ resin and $200 \mathrm{ml}$ water at $278 \mathrm{~K}$ within 10 minutes. The acidity of the as-synthesized silica sol with $\mathrm{pH}$ of 2 was adjusted to $\mathrm{pH}$ values between 3 and 8 by immediate adding of sodium hydroxide solution. $\mathrm{SiO}_{2}$ xerogels were obtained by drying of the washed hydrogels at $383 \mathrm{~K}$ for 24 hours and subsequent crushing.

\section{Solubility experiments}

$1 \mathrm{~g}$ silica gel was stirred at ambient temperature in $40 \mathrm{ml}$ of a $15 \%$ aqueous solution of TEAOH for $15-60$ minutes. Before ICP OES element analysis, the solution was separated from the solid by filtration over glass micro filters MF 100 (Fisherbrand) in a first step followed by the filtration using PTFE miro-membrans $(0.2 \mu \mathrm{m})$ under pressure within 5 minutes. The separation period was part of the total treatment time. The solubility of the glass filter material does not exceed 3 $\mathrm{mg} / \mathrm{l}$ and can be, therefore, neglected. Cellulose membranes were non-suitable for the separation procedure because the material dissolves itself under these conditions.

The filtrates were analyzed by use of a IRIS Intrepid High Resolution spectrometer (Thermo Elemental, USA). The ICP OES was calibrated within reference to synthesized solution standards. The accuracy of the measurements lies around 1-3\% within relative standard deviation (RSD) for values above background equivalent concentration (BEC). 


\section{Characterization of xerogels}

The ${ }^{29} \mathrm{Si}$ MAS NMR spectra were recorded at room temperature on a Bruker Avance 400 spectrometer, operating at frequencies of $79.5 \mathrm{MHz}$. A $4 \mathrm{~mm}$ double tuned $\left({ }^{1} \mathrm{H}-\mathrm{X}\right) \mathrm{MAS}$ probe (Bruker Biospin) was used to perform MAS NMR measurements at spinning rates of $12 \mathrm{kHz}$. The spectra were obtained with a single pulse excitation consisting of $4 \mu$ s pulses ( $\pi / 2$ pulses) and recycle delays of 120 seconds to exclude saturation effects. Measurements in the high power decoupling mode (HPDEC) brought no higher resolution of the signals. Up to 700 FIDs were accumulated to obtain reliable signal-to-noise ratio. The spectra were externally referenced to liquid $\mathrm{Me}_{4} \mathrm{Si}$ at $0 \mathrm{ppm}$. A detailed $\mathrm{Q}^{\mathrm{n}}$-group characterization includes the line shape analysis of the NMR spectra by use of an iterative deconvolution procedure with the help of dmfit software package [15].

IR absorption spectra were taken on a Shimadzu FTIR 8400S spectrometer with a resolution of $\pm 1 \mathrm{~cm}^{-1}$ by use of 30 scans. For analysis, $0.5 \mathrm{mg}$ of the sample was pressed with $400 \mathrm{mg}$ $\mathrm{KBr}$ into a pellet and measured in the IR range of $400 \mathrm{~cm}^{-1}$ to $4000 \mathrm{~cm}^{-1}$.

Scanning electron microscopy (SEM) was performed on a Hitachi S2400 with W cathode at the accelerating potential of $15-20 \mathrm{kV}$. To produce the conductive layer, the particles were sputtered by a thin gold coating.

Chemical element analysis was measured by using XRF spectrometer PW2404 from Panalytical. $0,5 \mathrm{~g}$ of the sample were fused with $3 \mathrm{~g}$ lithium borate $\left(\mathrm{Li}_{4} \mathrm{~B}_{6} \mathrm{O}_{11}\right.$ - Spectromelt A12 from Merck $\mathrm{GmbH}$ ) in a platinum crucible to cast a $27 \mathrm{~mm}$ diameter glass disc.

The BET surface area was determined on basis of the volumetric nitrogen adsorption at $\mathrm{p} / \mathrm{p}_{0}=$ $0.075,0.1$, and 0.125 at $-77.8 \mathrm{~K}$ on a Nova 1200 of the Quantachrome Corporation. 


\section{References}

[1] D.W. Breck, Zeolite Molecular Sieves, John Wiley \& Sons, London, 1974.

[2] R. Barrer, Hydrothermal Chemistry of Zeolites, Academic Press, London, 1982.

[3] E. Leibnitz, H. G. Struppe, Handbuch der Gaschromatographie, Akademische Verlagsanstalt, Leipzig, 1984.

[4] C. Mc Donagh, P. Bowe, K. Mongey, B. D. Mac Craith, J. Non-Cryst. Solids, 2002, 306,138 .

[5] A.O. Dieng, R.Z. Wang, Renew. Sustainable Energy Rev., 2001, 5, 313.

[6] E. H. Hauser, Silicic Science, Van Nostrand, Princeton, 1955.

[7] R. B. Sosman, The Phase of Silica, Rutgers University Press, New Brunswick, 1965.

[8] W. Hinz, Silicate: Grundlagen der Silicatwissenschaft und Silicattechnik, Vol. 2, Verlag Bauwesen, Berlin, 1971.

[9] R.K. Iler, The chemistry of silica, Wiley \& Sons, New York, 1979.

[10] G. Engelhardt, D. Michel, High Resolution Solid State NMR of Silicates and Zeolites, Wiley \& Sons, New York, 1987.

[11] C. Cannas, M. Casu, A. Musinu, G. Piccaluga, J. Non-Cryst. Solids, 2005, 351, 3476.

[12] J. Estella, J. C. Echeverria, M. Laguna, J. Garrido, Microp. Mesopor. Mater., 2007, $102,274$.

[13] A. Fidalgo, L. M. Ilharco, Microp. Mesopor. Mater., 2005, 84, 229.

[14] S.P. Zhdanov, S.S. Chvoshchev, N.N. Samulevich, Synthesized Zeolites, Gordon \& Breach Science Publishers, New York, 1990.

[15] D. Massiot, F. Fayon, M. Capron, I. King, S. Le Calvé, B. Alonso, J.O. Durand, B. Bujoli, Z. Gan, G. Hoatson, Magn. Reson. Chem. 40 (2002) 70 - 76

[16] E. M. Flanigen, in Zeolite Chem. Catal. Ed. J. A. Rabo, ACS Monographs 171 (1976) 81. 
[17] H. Fichtner-Schmittler, U. Lohse, H. Miessner, H. E. Maneck, Z. Phys. Chem. Leipzig 271 (1990) 69.

[18] C. H. Rüscher, J.-Chr. Buhl, W. Lutz, in A. Galarneau, F. Di Renzo, F. Fajula, and J. Vedrine (Eds.), Stud. Surf. Sci. Cat., Vol. 135, Elsevier, Amsterdam, 2001, 13-P15, p. 1 . 
Table 1 Chemical and physical data of used commercial and synthesized silica gels

\begin{tabular}{|c|c|c|c|c|c|c|c|}
\hline $\begin{array}{c}\text { sample } \\
\text { denotation }\end{array}$ & $\begin{array}{l}\text { sample } \\
\text { type }\end{array}$ & $\begin{array}{c}\text { particle } \\
\text { size }^{1} \\
\mu \mathrm{m}\end{array}$ & $\begin{array}{c}\text { BET } \\
\text { surface } \\
\mathrm{m}^{2} / \mathrm{g}\end{array}$ & $\begin{array}{c}\text { IR } v_{\text {TOT }}, \\
\mathrm{cm}^{-1}\end{array}$ & $\begin{array}{c}\text { portion of } \\
\mathrm{Q}^{4}\end{array}$ & $\begin{array}{c}{ }^{29} \mathrm{Si} \text { MAS } \\
\text { of Q- } \\
\mathrm{Q}^{3}\end{array}$ & $\begin{array}{l}\text { NMR } \\
\text { groups, \% } \\
\mathrm{Q}^{2}\end{array}$ \\
\hline \multicolumn{8}{|c|}{ commercial silica gels } \\
\hline Promeksil B12 & precipitated & $\leq 10$ & 413 & 1101 & 70 & 26 & 4 \\
\hline Sipernat 320 & precipitated & $\leq 75$ & 196 & 1107 & 80 & 17 & 3 \\
\hline Aerosil 200 & pyrogene & $\leq 310$ & 210 & 1110 & 85 & 15 & 0 \\
\hline Silica 995 & pyrogene & $\leq 28$ & 61 & 1117 & 93 & 7 & 0 \\
\hline Aerosil OX 50 & pyrogene & $\leq 34$ & 42 & 1120 & 94 & 6 & 0 \\
\hline \multicolumn{8}{|c|}{ synthesized silica gels } \\
\hline $\mathrm{SiO}_{2}(\mathrm{pH} 2)$ & precipitated & $\leq 380$ & 538 & 1082 & 54 & 41 & 5 \\
\hline $\mathrm{SiO}_{2}(\mathrm{pH} 3)$ & precipitated & $\leq 285$ & 513 & 1088 & 56 & 39 & 5 \\
\hline $\mathrm{SiO}_{2}(\mathrm{pH} 4)$ & precipitated & $\leq 105$ & 507 & 1095 & 61 & 34 & 5 \\
\hline $\mathrm{SiO}_{2}(\mathrm{pH} 5)$ & precipitated & $\leq 95$ & 404 & 1101 & 71 & 24 & 5 \\
\hline $\mathrm{SiO}_{2}(\mathrm{pH} 6)$ & precipitated & $\leq 110$ & 352 & 1105 & 74 & 24 & 2 \\
\hline $\mathrm{SiO}_{2}(\mathrm{pH} 7)$ & precipitated & $\leq 910$ & 172 & 1103 & 81 & 17 & 2 \\
\hline $\mathrm{SiO}_{2}(\mathrm{pH} 8)$ & precipitated & $\leq 115$ & 140 & 1105 & 80 & 19 & 1 \\
\hline
\end{tabular}

${ }^{1}$ estimated from SEM with an error of $\pm 5 \%$ 
Fig. 1 Alkaline solubility of commercial silica gels in dependence on time

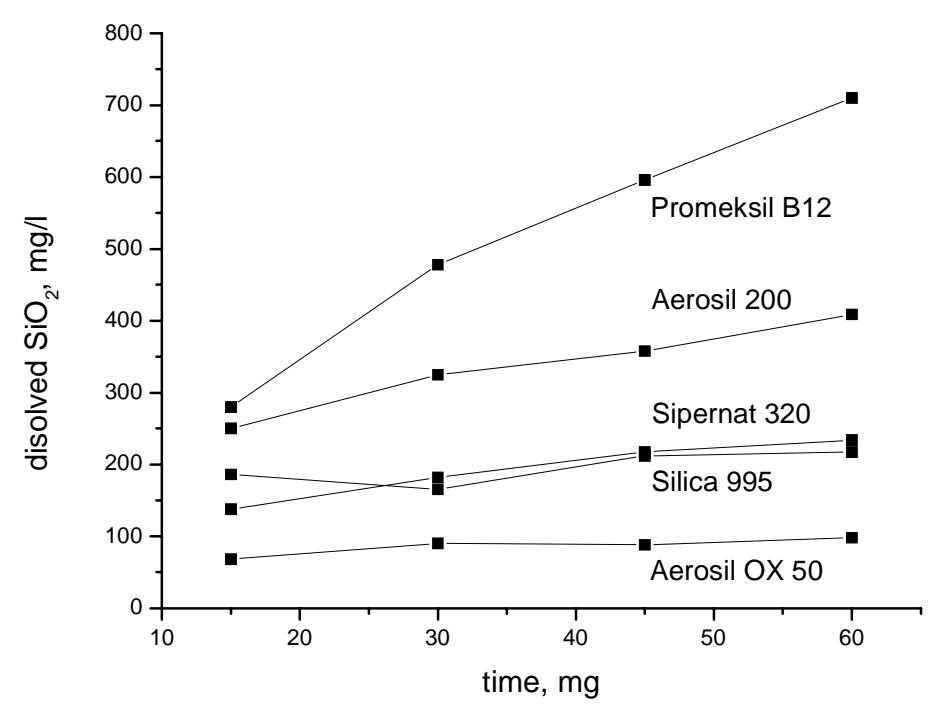


Fig. 2 Alkaline solubility of synthesized silica gels in dependence on time

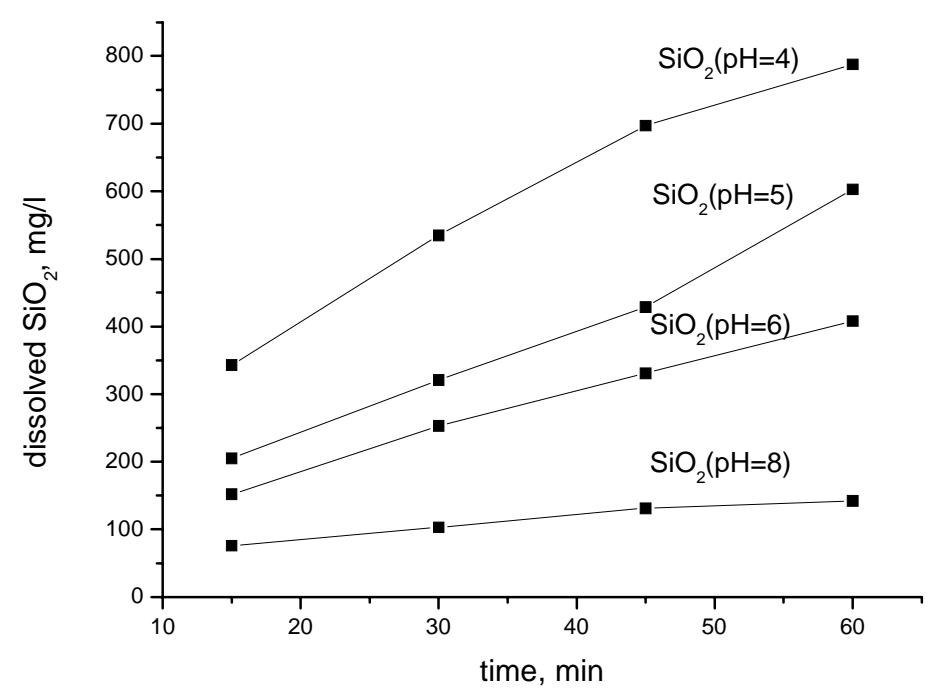


(a)

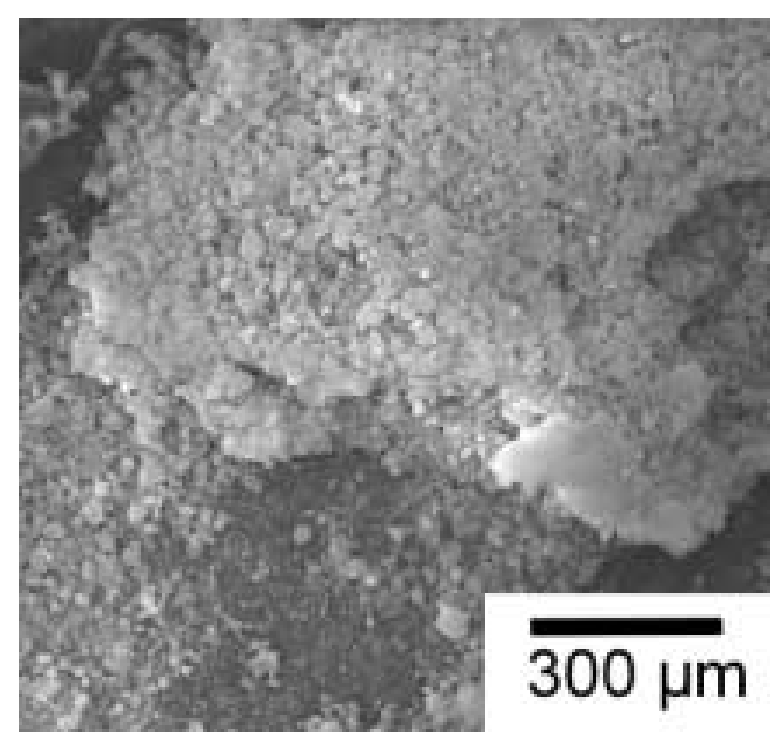

(c)

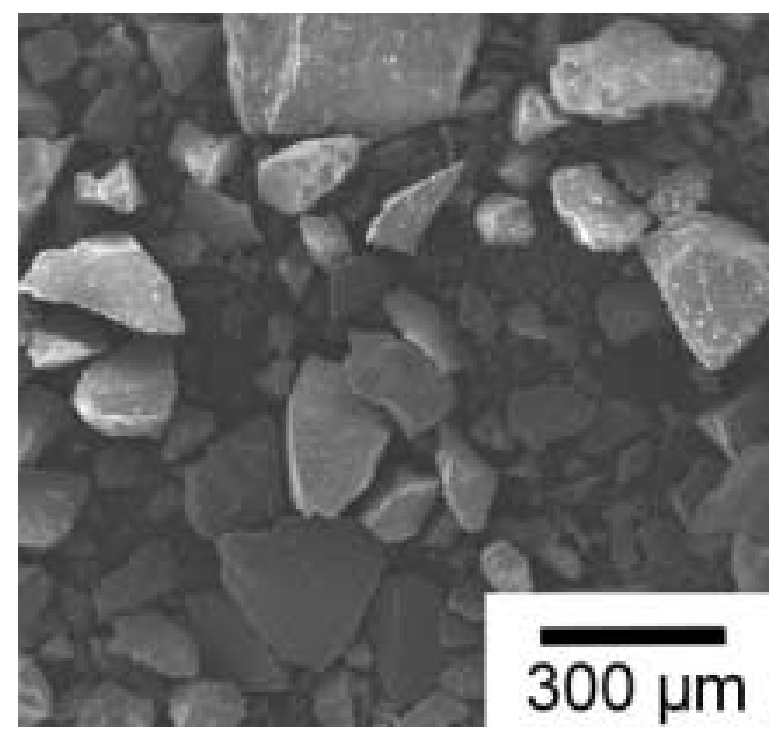

(b)

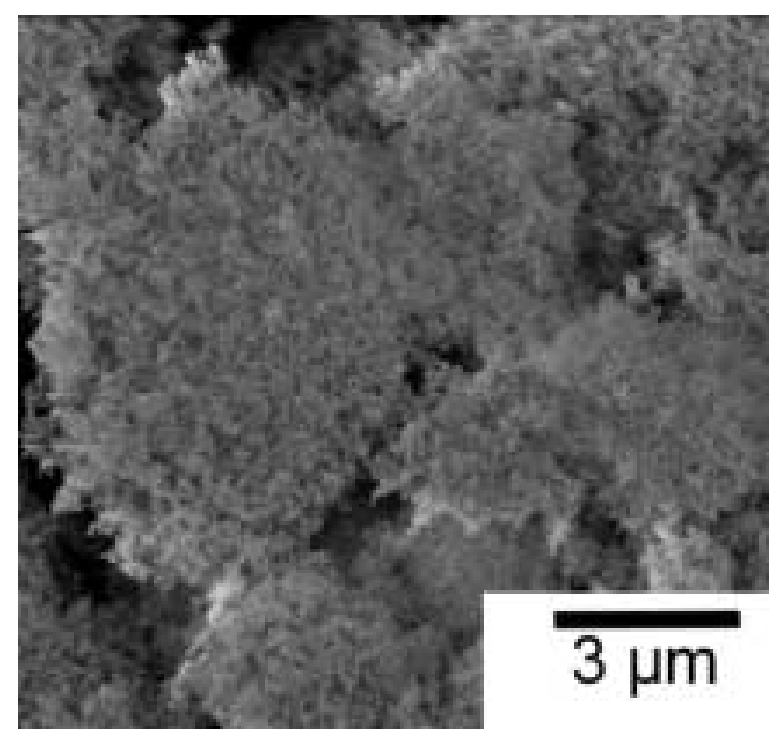

(d)

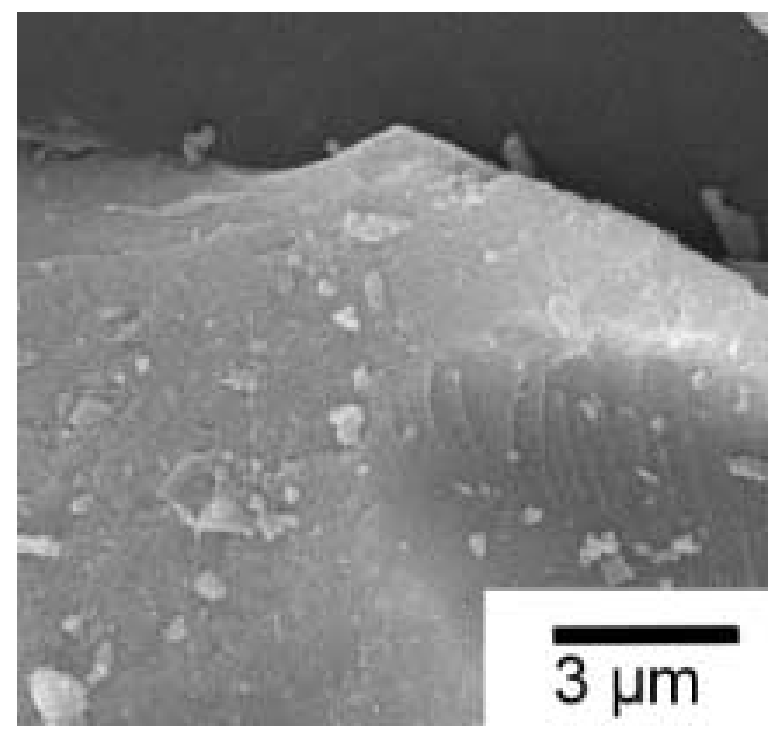


Fig. 4 Influence of the BET surface on the alkaline solubility of commercial silica gels after 60 min stirring

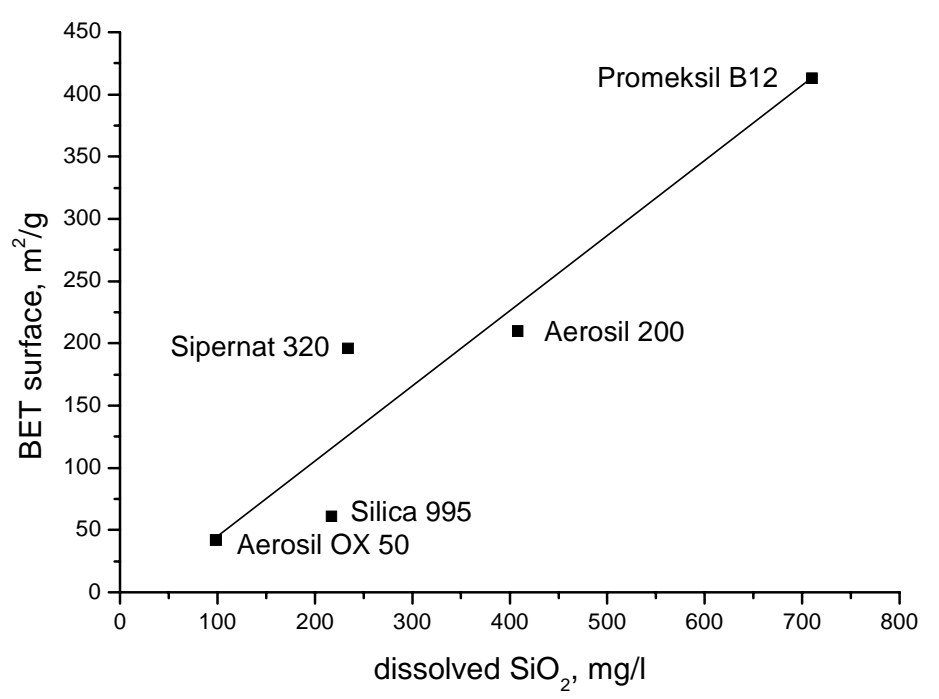


Fig. 5 Influence of the BET surface on the alkaline solubility of synthesized silica gels after 60 min stirring

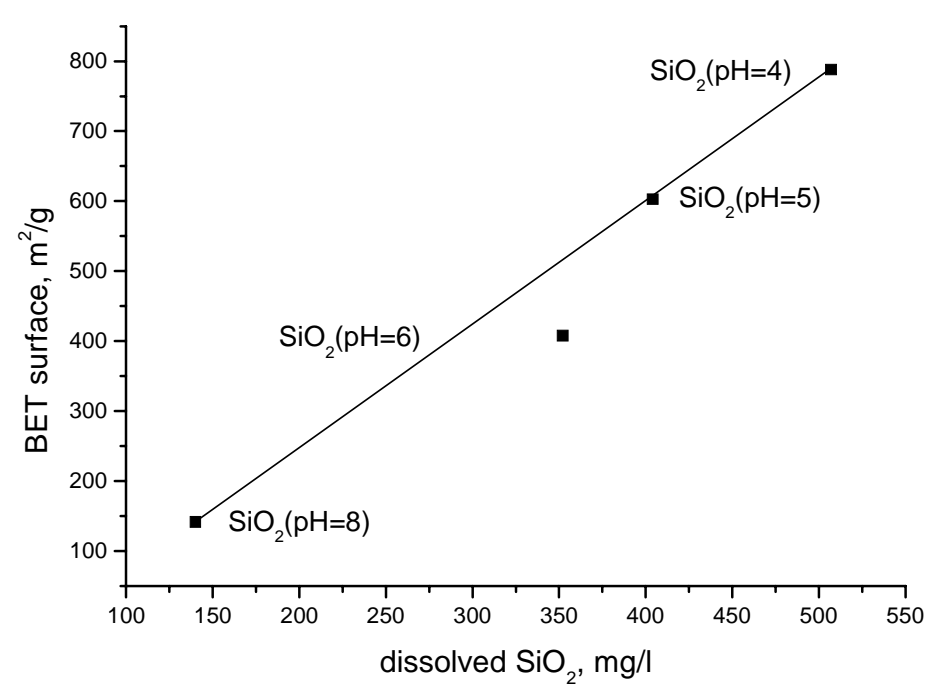

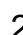

3 
Abb. $6 \quad{ }^{29}$ Si MAS NMR spectra of the commercial silica gels

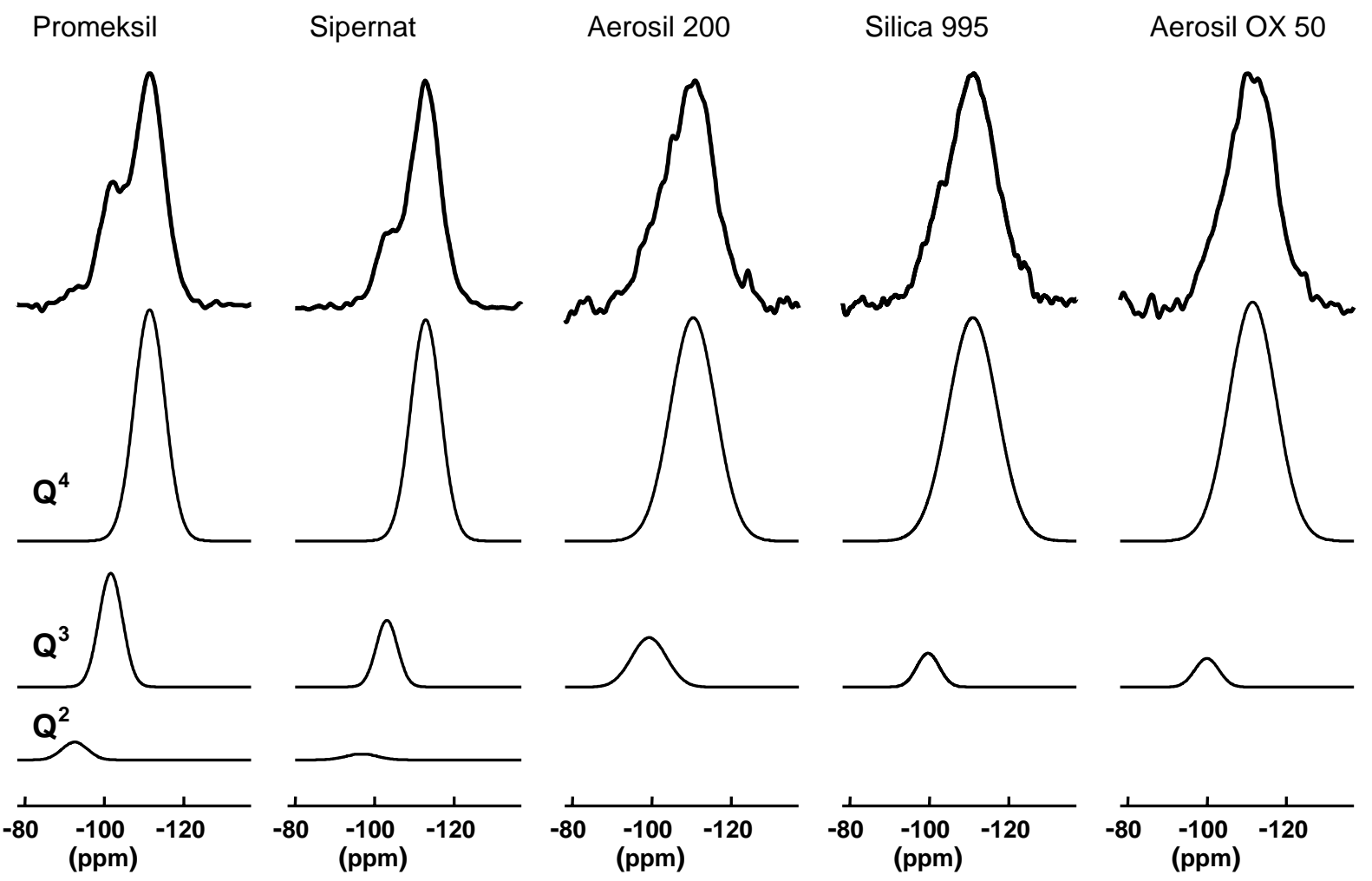


Abb. $7 \quad{ }^{29} \mathrm{Si}$ MAS NMR spectra of the synthesized silica gels in dependence of the $\mathrm{pH}$ value
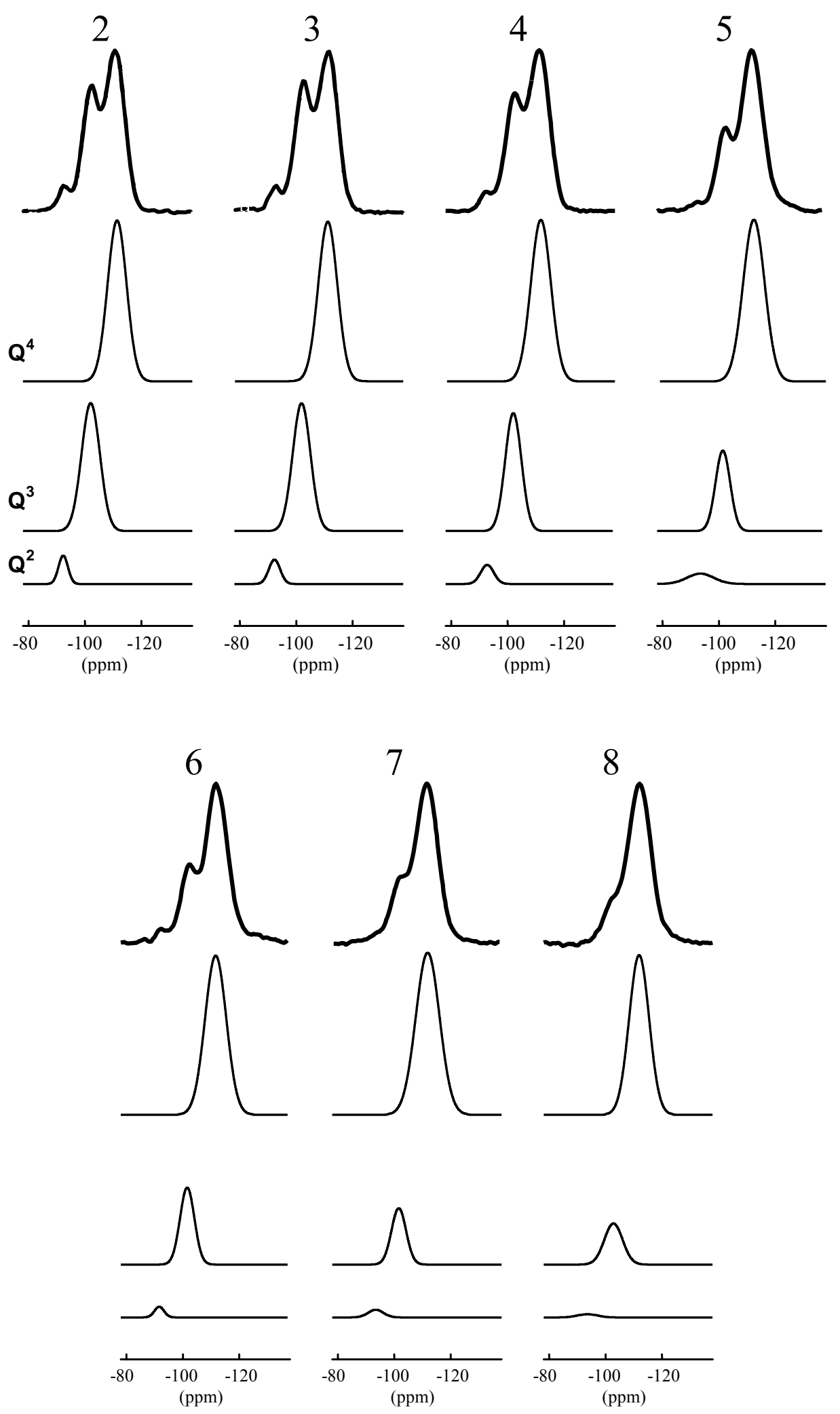
Abb. 8 IR spectra of two selected commercial and synthesized silica gel samples

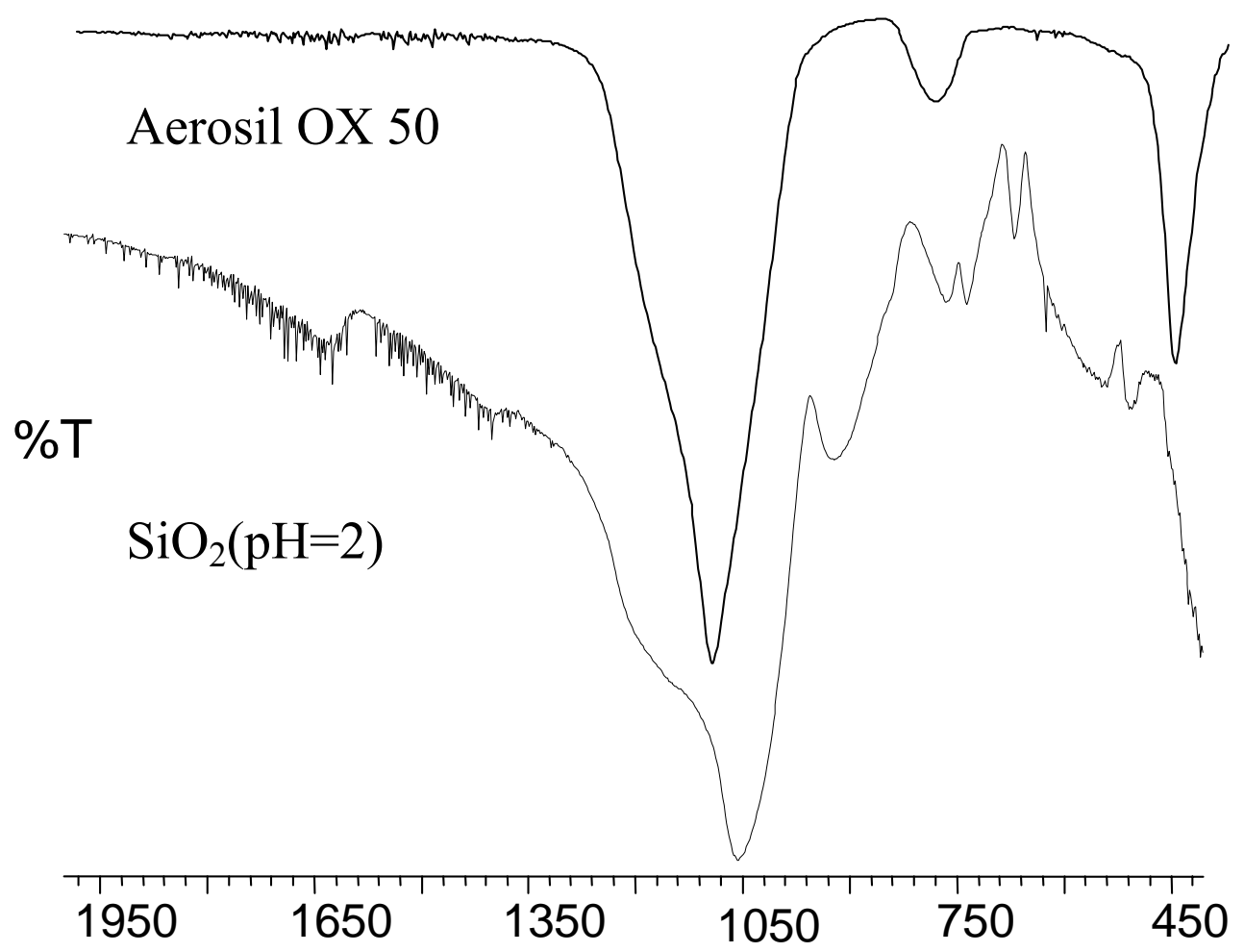

